\title{
Clostridium Perfringens Sepsis With Massive Intravascular Haemolysis: A Rare Presentation
}

\author{
Carolina Paulino ${ }^{\mathrm{a}, \mathrm{c}}$, Joana Silvestre ${ }^{\mathrm{a}, \mathrm{b}}$, Joao Goncalves Pereira ${ }^{\mathrm{a}, \mathrm{b}}$, \\ Camila Tapadinhas ${ }^{\mathrm{a}}$, Vitor Mendes ${ }^{\mathrm{a}}$, Pedro Povoa ${ }^{\mathrm{a}, \mathrm{b}}$
}

\begin{abstract}
Massive intravascular haemolysis is a rare but well-known complication of Clostridium perfringens sepsis. Presence of fever, intravascular haemolysis, numerous spherocytes in peripheral blood smear and septic shock should raise this clinical suspicion. We describe the case of a 66-year-old male who was admitted in the Emergency Room complaining of abdominal pain, vomiting, fever and dark red urine. No relevant findings in physical examination were found. Laboratory tests revealed massive intravascular haemolysis (minimum haemoglobin of $4 \mathrm{~g} / \mathrm{dL}$ ). Ultrasound of the upper abdomen did not show relevant findings. Six hrs later his clinical condition suddenly deteriorated, evolving to septic shock. He was promptly admitted in the Intensive Care Unit but his condition continued to deteriorate very rapidly, with severe multiple organ failure. He died a few hrs later despite full organ support and large spectrum antibiotic therapy. Clostridium perfringens was identified in blood cultures taken before death. The post-mortem evaluation revealed a high stage of body decomposition suggesting presence of gas-producing bacteria precluding the execution of the autopsy. Though this is a very rare clinical condition, the suspicion of clostridium sepsis mandates the immediate prescription of antibiotic therapy and aggressive focus control in order to change the dismal prognosis associated with this entity.
\end{abstract}

Keywords: Clostridium perfringens; Sepsis; Intravascular haemolysis

\footnotetext{
Manuscript accepted for publication February 23, 2012

${ }^{a}$ Polyvalent Intensive Care Unit, Sao Francisco Xavier Hospital, CHLO, Lisbon, Portugal

${ }^{\mathrm{b}}$ CEDOC, Faculty of Medical Sciences, New University of Lisbon, Lisbon, Portugal

${ }^{\mathrm{c}}$ Corresponding author: Carolina Paulino, Unidade de Cuidados Intensivos Polivalente, Hospital de Sao Francisco Xavier; Centro Hospitalar de Lisboa Ocidental, Estrada do Forte do Alto do Duque; 1449-005 Lisboa, Portugal. Email: carolina_paulino@hotmail.com

doi: $10.4021 / \mathrm{jmc} 583 \mathrm{w}$
}

\section{Introduction}

Clostridium perfringens (C. perfringens), formerly known as Clostridium welchii, is an anaerobic Gram-positive sporeforming bacillus [1]. It is amongst the most pathogenic species of Clostridium species, alongside with Clostridium botulinum, Clostridium tetani and Clostridium difficile.

C. perfringens can be found in samples of water, soil, and it is present in gastro-intestinal tract of healthy animals as well as in humans. It has also the ability to cause disease in humans and animals, with a rapid growth of bacterial inoculum with spore and toxins formation. There are five biotypes of $C$. perfringens, based on the type of toxin that is produced, type A, B, C, D and E [2]. The main toxin is the $\alpha$-toxin, an enzyme that splits lecithin into phosphocholine and diglyceride, causing damage to red blood cell membrane, accounting for development of spherocytosis and subsequent intravascular haemolysis [3]. The clinical presentation of C. perfringens infection includes a variety of manifestations, such as gas gangrene, emphysematous cholecystitis, crepitant cellulitis, fasciitis and myositis. It is frequently associated with septic shock and intravascular haemolysis [4-5].

The diagnosis of intravascular haemolysis by $C$. perfringens should be suspected in the presence of acute anaemia with a raised mean cell haemoglobin concentration and a reduced mean cell volume, spherocytosis, negative indirect and direct Coombs test, haemoglobinemia and haemoglobinuria. It is also associated with Gram-positive rods on Gram stain of a peripheral blood smear and positive blood or tissue culture. A plain radiograph of the abdomen may reveal the presence of abscess or gas in tissues [1].

We report a case of a man that die with a $C$. perfringens sepsis with massive intravascular haemolysis, $22 \mathrm{hrs}$ after the onset of symptoms.

\section{Case Report}

A 66-year-old male was admitted in the Emergency Room of our hospital with a 12 hrs history of fever, abdominal pain, vomiting and dark red urine. He had a past medical history 
Table 1. Laboratory Data

\begin{tabular}{|c|c|c|c|}
\hline & $\begin{array}{l}\text { Hospital } \\
\text { admission }\end{array}$ & $\begin{array}{l}4 \text { hrs after ICU } \\
\text { admission }\end{array}$ & $\begin{array}{l}6 \mathrm{hrs} \text { after } \\
\text { ICU admission }\end{array}$ \\
\hline Red blood cells $\left(\times 10^{12} / \mathrm{L}\right)$ & 4.63 & & 2.83 \\
\hline Haemoglobin (g/dL) & 14.4 & & 4 \\
\hline Haematocrit (\%) & 42.9 & & 15.7 \\
\hline Mean cell volume (fL) & 92.6 & & \\
\hline Mean globular volume (pg) & 31.1 & & \\
\hline White cell count $\left(\times 10^{9} / \mathrm{L}\right)$ & 24,600 & & 22,200 \\
\hline Platelet count $\left(\times 10^{9} / \mathrm{L}\right)$ & 175,000 & & 52,000 \\
\hline Prothrombin time (sec) & 13.2 & & $>120$ \\
\hline Fibrinogen $(\mathrm{g} / \mathrm{L})$ & & & $<0.5$ \\
\hline Lactate dehydrogenase(U/L) & 4,953 & & 30,682 \\
\hline Haptoglobin (mg/dL) & & 56 & 49 \\
\hline C-reactive protein $(\mathrm{mg} / \mathrm{dL})$ & 6.93 & 6.18 & \\
\hline Urea (mg/dL) & 68 & & \\
\hline Creatinine $(\mathrm{mg} / \mathrm{dL})$ & 1.55 & 2.72 & 3.30 \\
\hline Alanine transaminase (U/L) & 527 & 474 & 553 \\
\hline Aspartate transaminase (U/L) & 593 & 1,476 & 1,284 \\
\hline Alkaline phosphatase (U/L) & 90 & & \\
\hline$\gamma$-glutamyltransferase (U/L) & 513 & 471 & \\
\hline Total bilirrubin (mg/dL) & 6.89 & 32.6 & 36.5 \\
\hline Direct bilirrubin (mg/dL) & 0.43 & 6.20 & 9.90 \\
\hline
\end{tabular}

of hypertension, type II diabetes mellitus, dyslipidemia, hyperuricemia and nephrolithiasis. He reportedly did not have travelled abroad namely to malaria endemic areas.

At admission, his core temperature was $38^{\circ} \mathrm{C}$, pulse rate was 106/minute, blood pressure was $157 / 67 \mathrm{mmHg}$. Physical examination was normal with the exception of moderate pain on palpation of the epigastric and right flank zone but without signs of peritoneal irritation.

In the initial hemogram (Table 1), haemoglobin concentration and platelet count were within the normal range with an elevation of white blood cell count. Biochemical screening showed elevation of total bilirrubin, direct bilir- 


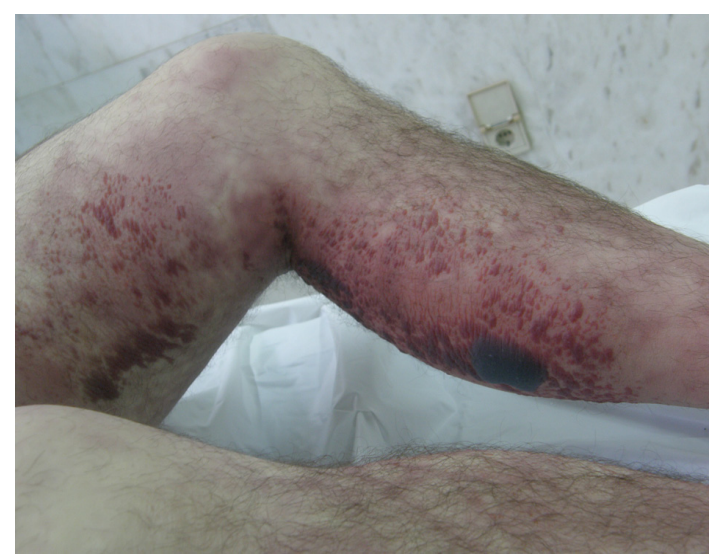

Figure 1. Body decomposition. Picture from the patient's leg taken $12 \mathrm{hrs}$ after his death. It shows the advanced state of body decomposition with gaseous destruction of tissues and formation of haemorrhagic blisters, suggesting the presence of gas-producing bacteria.

rubin, lactate dehydrogenase, serum aspartate transaminase, serum alanine transaminase, alkaline phosphatase and $\gamma$-glutamyltransferase. Urine analysis showed the presence of hemoglobinuria without haematuria.

A peripheral blood smear revealed spherocytosis and absence of schizocytes. The direct and indirect Coombs tests were negative. Plasmodium was not detected in microscopic examination of blood. Electrocardiogram and chest X-rays were normal. Abdominal ultrasound was performed and showed no relevant findings.

A few hours later the patient remained febrile $\left(38^{\circ} \mathrm{C}\right)$, tachycardic and became dyspneic. Arterial blood gases revealed severe metabolic (lactic) acidosis with $\mathrm{pH}$ 7.33; $\mathrm{HCO}_{3} 12.2 \mathrm{mmol} / \mathrm{L} ; \mathrm{PaCO}_{2} 16.4 \mathrm{mmHg} ; \mathrm{PaO}_{2} 51 \mathrm{mmHg}$; $\mathrm{SaO}_{2} 90.8 \%$, lactate $10.4 \mathrm{mmol} / \mathrm{L}$. Antibiotic therapy was started with piperacilin/tazobactam $4.5 \mathrm{~g}$ ev qid.

He was promptly admitted to our ICU with the diagnosis of massive intravascular haemolysis. His condition deteriorated very rapidly, with the development of multiple organ failure.

He was intubated and invasive mechanical ventilation was started. Large doses of vasopressor agents were given and renal replacement therapy was immediately started, without any significant clinical improvement. The second chest $\mathrm{x}$-ray showed diffuse bilateral pulmonary infiltrates and severe hypoxemia $\left(\mathrm{PaO}_{2} / \mathrm{FiO}_{2}\right.$ ratio - $\left.43.9 \mathrm{mmHg}\right)$, compatible with Acute Respiratory Distress Syndrome. Laboratory data in the subsequent hours following ICU admission revealed very low levels of haemoglobin concentration and platelet count, low haptoglobin and a marked increase in creatinine and transaminases (Table 1).

Coagulation tests were compatible with disseminated intravascular coagulation.

Despite intensive therapy and supportive care, the pa-

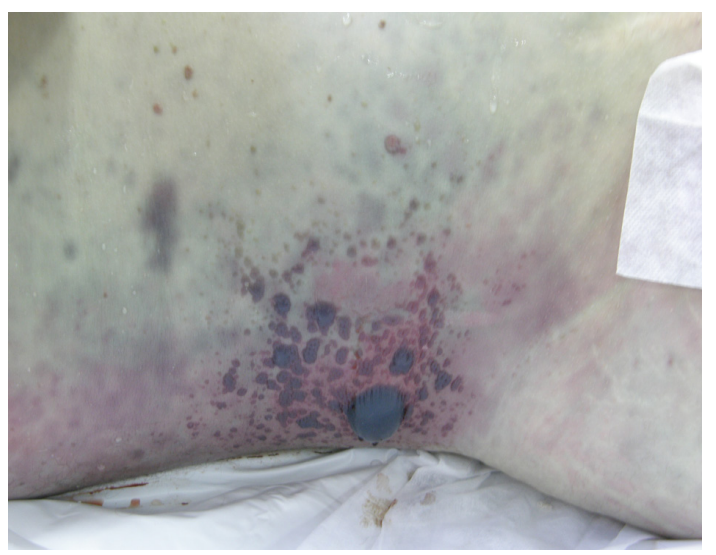

Figure 2. Body decomposition. Picture from the patient's right abdominal flank taken $12 \mathrm{hrs}$ after his death. It shows the advanced state of body decomposition with gaseous destruction of tissues and formation of haemorrhagic blisters, suggesting the presence of gas-producing bacteria.

tient died $22 \mathrm{hrs}$ after the onset of symptoms and $10 \mathrm{hrs}$ after hospital admission. The performance of an exchange transfusion was considered but the rapid and severe courses of the disease preclude its implementation.

The definitive diagnosis of $C$. perfringens sepsis was made after its identification in blood cultures for anaerobes, performed before death. The blood cultures for aerobes were sterile. Autopsy was not performed because of the advanced decomposition of the body, that took place in less then 24 hrs after death, which also pointed to the presence of gasproducing bacteria (Fig. 1).

\section{Discussion}

The authors present a very rare case of septic shock caused by $C$. perfringens bacteraemia, complicated with massive intravascular haemolysis.

Massive intravascular haemolysis is a rare but wellknown complication of $C$. perfringens bacteraemia, occurring in 7 to $15 \%$ of cases [6], and has been considered as the most significant and unfavourable prognostic sign associated with this infection [3].

There are only a small number of diseases that cause massive intravascular haemolysis, either infectious or noninfectious. Among the infectious causes one should consider malaria, but also clostridial bacteraemia and other rare conditions, such as bartonellosis and babesiosis as possible aetiologies [7]. Nevertheless, with the exception of clostridium bacteraemia, these infectious diseases are usually straightforward to diagnose and can normally be easily excluded because of their particular epidemiology. Non-infectious causes of intravascular haemolysis include haemolytic transfusion reactions, paroxysmal nocturnal haemoglobinuria, 
haemolytic uremic syndrome (HUS) or haemolysis caused by snake venoms.

In our patient, the possibility of HUS was raised, since this can be associated with acute renal failure, thrombocytopenia and haemolysis. However, our patient blood smear showed spherocytes, not schizocytes typically present in this syndrome. Moreover there was no other evidence of microangiopatic haemolytic anaemia that is also characteristically present in HUS.

The diagnosis of $C$. perfringens sepsis is difficult without its identification in blood cultures [8]. If clostridium bacteraemia is suspected, antibiotics should be started immediately, including high-dose penicillin (up to 30 million units per day) or tetracycline (if $\beta$-lactam allergy is suspected). In the presence of gas gangrene, clindamycin is also recommended. Chloramphenicol, doxycycline, imipenem and metro-nidazole are also alternative agents [1]. If there is a perceived infection focus, large and rapid surgical debridement is part of the initial approach [6].

Finally two additional therapeutic options must be considered: exchange transfusion and hyperbaric oxygen therapy. Exchange transfusion could be beneficial at an early stage of intravascular haemolysis by removing toxin-damaged red cells, free haemoglobin and fibrin split products [1, 9]. The beneficial effect of hyperbaric oxygen therapy has been reported in several case series since an oxygen-rich environment promotes the death of $\mathrm{C}$. perfringens and blocks the production of toxins [1].

Van Bunderen et al. reviewed 40 cases of $C$. perfringens septicaemia with massive intravascular haemolysis published in the literature since 1990 [6]. They found that $37.5 \%$ of patients had no underlying condition related to this infectious disease. The most common associated diseases were haematological disorders $(22.5 \%)$, pancreatic or gastric cancer $(12.5 \%)$. Diabetes was present in $30 \%$ of the patients, being the only risk factor in $15 \%$. The focus of infection was mostly hepatobiliary (45.0\%), being intestinal in $17.5 \%$. A gynaecological origin, after an invasive procedure, was found in $10 \%$ of the cases [10]. The mortality rate was very high, ranging between $70-100 \%[1,7]$. In the large majority of cases the definite diagnosis was confirmed only after death [3], as it was our case.

The present case is particular and rare since it was complicated with massive intravascular haemolysis, with an extremely rapid clinical course, without identification of an obvious infectious focus, in a patient with only one predisposing factor (diabetes).

\section{Conclusion}

Despite all the medical treatments and organ support, our patient presented a very severe septic shock and had a fatal outcome.

The severity of $C$. perfringens infections, associated with a high mortality rate, reinforce the importance of rapid clinical diagnosis and, above all, immediate antibiotic therapy and focus control, when appropriate.

\section{Conflict of Interest}

The authors declare that they have no conflicts of interest.

\section{Grant Support}

There were no sources of funding for this research.

\section{References}

1. Rajendran G, Bothma P, Brodbeck A. Intravascular haemolysis and septicaemia due to Clostridium perfringens liver abscess. Anaesth Intensive Care. 2010;38(5):942945.

2. Morris WE, Fernandez-Miyakawa ME. [Toxins of Clostridium perfringens]. Rev Argent Microbiol. 2009;41(4):251-260.

3. Ohtani S, Watanabe N, Kawata M, Harada K, Himei M, Murakami K. Massive intravascular hemolysis in a patient infected by a Clostridium perfringens. Acta Med Okayama. 2006;60(6):357-360.

4. Kapoor JR, Monteiro B, Tanoue L, Siegel MD. Massive intravascular hemolysis and a rapidly fatal outcome. Chest. 2007;132(6):2016-2019.

5. Rogstad B, Ritland S, Lunde S, Hagen AG. Clostridium perfringens septicemia with massive hemolysis. Infection. 1993;21(1):54-56.

6. van Bunderen CC, Bomers MK, Wesdorp E, Peerbooms $\mathrm{P}$, Veenstra J. Clostridium perfringens septicaemia with massive intravascular haemolysis: a case report and review of the literature. Neth J Med. 2010;68(9):343-346.

7. Pun $\mathrm{KC}$, Wehner JH. Abdominal pain and massive intravascular hemolysis in a 47-year-old man. Chest. 1996;110(5):1353-1355.

8. Fujita H, Nishimura S, Kurosawa S, Akiya I, NakamuraUchiyama F, Ohnishi K. Clinical and epidemiological features of Clostridium perfringens bacteremia: a review of 18 cases over 8 year-period in a tertiary care center in metropolitan Tokyo area in Japan. Intern Med. 2010;49(22):2433-2437.

9. Uppal A, Hymes K, Schwartz DR. A 61-year-oldman with massive intravascular hemolysis. Chest. 2009;136(5):1424-1427.

10. Bryant CS, Perry L, Shah JP, Kumar S, Deppe G. Lifethreatening clostridial sepsis in a postmenopausal patient with degenerating uterine leiomyoma. Case Report Med. 2010;2010:541959. 